\title{
Aplikasi Algoritma Dijkstra dalam Penyelesaian Berbagai Masalah
}

\author{
Rosyid Ridlo Al Hakim ${ }^{1 *}$, Muhammad Haikal Satria ${ }^{1}$, Yanuar Zulardiansyah Arief ${ }^{1}$, \\ Agung Pangestu ${ }^{1}$, Ariep Jaenul ${ }^{1}$, Revita Desi Hertin ${ }^{2}$, Dian Nugraha ${ }^{3}$ \\ ${ }^{1}$ Jurusan Teknik Elektro, Fakultas Teknik dan Sistem Informasi \\ ${ }^{2}$ Jurusan Bisnis Digital, Fakultas Ekonomi dan Bisnis \\ ${ }^{3}$ Jurusan Sistem Informasi, Fakultas Teknik dan Sistem Informasi \\ Universitas Global Jakarta, Jakarta, Indonesia \\ rosyidridlo@student.jgu.ac.id
}

\begin{abstract}
ABSTRAK - Dijkstra is a greedy algorithm that gives a choice of several available shortest routes and then provides a solution. The application of Dijkstra's Algorithm in everyday life is very diverse. This study collects research results regarding the application of Dijkstra's Algorithm to solve everyday problems such as the shortest path problem, this mini-review paper can explain the study of Dijkstra's Algorithm for various things, including solving bi-objective shortest routes, multi-objective routes, emergency evacuation, Dijkstra's graph, the connection between LBS features, best route distribution, and fuzzy solution.
\end{abstract}

Keywords: Algorithm, Dijkstra, Shortest Routes, Shortest Path

\section{PENDAHULUAN}

Sebuah algoritma yang dapat digunakan untuk penentuan rute terpendek suatu lokasi berupa Algoritma Dijkstra. Algoritma Dijkstra dapat menentukan jarak terpendek dari beberapa rute yang tersedia [1], [2]. Penentuan rute terpendek dengan Algoritma Dijkstra salah satu contohnya menentukan arah tempuh rumah sakit terdekat [3] dan mencari rute terdekat lapangan futsal [2].

Algoritma Dijkstra adalah tipe greedy algorithm dengan prinsip yang memilih minimum services pada beberapa jarak yang ada dan memberikan beberapa solusi jarak terpendek. Penelitian [2] mencoba menentukan jalur terpendek menuju lapangan futsal terdekat di Kota Pangkal Pinang, Pulau Bangka, Republik Indonesia. Algoritma ini dapat menentukan rute tercepat menuju lapangan futsal terdekat sesuai titik pengguna di peta melalui smartphone.

Aplikasi Algoritma Dijkstra banyak digunakan dalam berbagai keperluan sehari-hari. Algoritma Dijkstra memberikan opsi jarak-jarak yang ada pada sistem, lalu sistem memilih jarak yang terdekat dengan waktu ditempuh tercepat dan memberikan tampilan maps kepada user. Algoritma Dijkstra dapat menghasilkan nilai waktu yang efisien dalam perhitungan jarak antara sistem apabila dibandingkan dengan perhitungan manual yaitu tidak jauh berbeda jaraknya, dan setiap jalur wisata yang dipilih oleh pengguna dapat ditempuh dengan berbagai kecepatan [1].

Algoritma Dijkstra sangat efektif dalam menghitung rute terpendek antara dua titik persimpangan pada posisi geografis, ini diterapkan dalam indeks geofence. Pentingnya penentuan rute terpendek pada di dua titik yang ada pada posisi geografis akan meningkatkan fitur Location-based Services (LBS) yang terdapat dalam perangkat smartphone
[4]. Dikarenakan penerapan Algoritma Dijkstra yang sangat beragam, maka penelitian ini menghimpun beberapa penelitian terdahulu yang menerapkan pemanfaatan Algoritma Dijkstra dalam penyelesaian berbagai kasus, diharapkan penelitian mini-review ini bisa berguna untuk para researcher yang akan menerapkan Algoritma Dijkstra untuk berbagai keperluan dalam menyelesaikan persoalan sehari-hari.

\section{METODOLOGI}

A. Diagram Alir Penelitian

Diagram alir penelitian (flowchart) mengacu pada [5], terdiri atas beberapa tahapan yang dilakukan secara komprehensif. Tahapan-tahapan ini dilakukan guna mendapatkan hasil review yang mendalam berdasarkan artikel-artikel yang dipilih. Diagram alir penelitian ini secara lebih detail dijelaskan dalam Gambar 1.

1) Studi Literatur

Alur penelitian diawali dengan studi literatur dari jurnal-jurnal ter-indeks $S$ copus, penelitian ini mendapatkan 42 artikel. Artikel-artikel ini berdasarkan penelusuran lebih lanjut berdasarkan keywords yang ada di setiap artikel. Untuk memfokuskan pencarian maka penelusuran terbatas pada keywords "Dijkstra Algorithm; Shortest Path; Fastest Route".

\section{2) Identifikasi}

Penelusuran Selanjutnya, identifikasi judul yang sesuai dengan cakupan mini-review pada artikel ini. Identifikasi judul berkaitan dengan keywords untuk setiap artikel dipilih. Dari 42 artikel, judul-judul yang teridentifikasi untuk dilakukan tahapan lebih lanjut berdasarkan pada kesesuaian judul dengan topik penggunaan Algoritma Dijkstra. 
3) Screening Abstrak Sesuai

Setelah judul-judul artikel yang sesuai dipilih, screening setiap judul yang dipilih berdasarkan abstrak, sehingga didapatkan 10 artikel yang sesuai. Abstrak setiap artikel menjadi gambaran secara rinci mengenai bahasan artikelnya. Abstrak yang dipilih disesuaikan dengan tujuan penulisan mini-review ini yaitu membahas mengenai pemanfaatan Algoritma Dijkstra untuk berbagai keperluan atau masalah.

4) Seleksi Full-text

Tahapan selanjutnya dilanjutkan dengan membaca full-text setiap artikel dan dilakukan proses mini-review.
Artikel berjumlah 10 ini sudah melalui tahapan yang komprehensif dalam penyeleksiannya. Untuk membatasi cakupan bahasan pada mini-review ini, artikel dipilih karena kebaharuan cakupan implementasi Algoritma Dijkstra dalam menangani suatu masalah yang timbul. Artikel minireview ini hanya membahas secara kecil berbagai penelitian yang ada sebelumnya (10 artikel) yang terkait dengan penggunaan Algoritma Dijkstra untuk berbagai masalah, namun akan lebih baik untuk memahami setiap artikel yang dijadikan mini-review dapat dilakukan penelusuran artikel yang bersangkutan untuk kemudian dilakukan pembacaan full-text demi mendapatkan pemahaman yang menyeluruh untuk artikelnya.

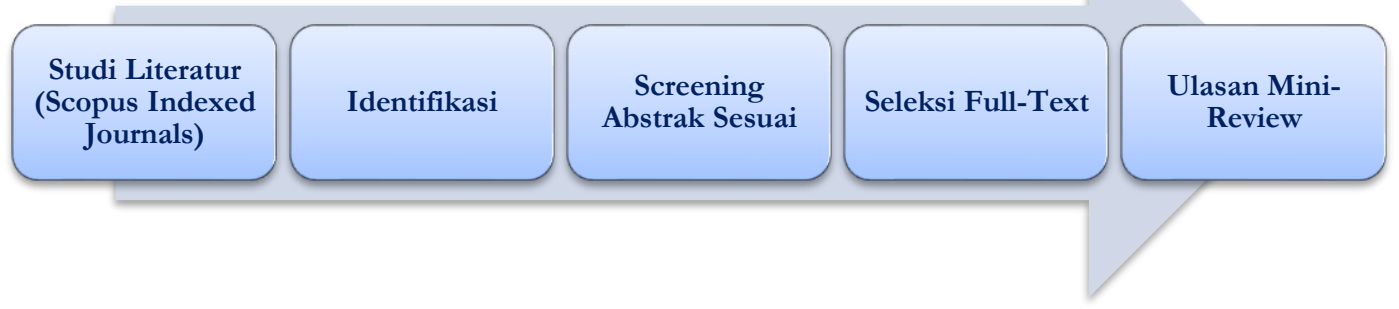

Gambar 1. Diagram Alir (flowchart) Penelitian

\section{HASIL DAN PEMBAHASAN}

Hasil pencarian didapatkan 10 artikel publikasi tahun 2012-2020 yang terdiri atas 4 publikasi prosiding konferensi internasional [4], [5], [6], [7]. Enam artikel hasil penelitian [8], [9], [10], [11], [12], [13]. Kesepuluh artikel ini dipilih karena sesuai dengan tujuan mini-review pada artikel ini yaitu untuk mendapatkan informasi mengenai implementasi Algoritma Dijkstra untuk menyelesaikan suatu permasalahan.

Algoritma Dijkstra menawarkan node-node yang dilalui untuk menentukan shortest path dari node pertama ke node terakhir. Berdasarkan nilai minimum bobot bagian yang diberikan pada serangkaian tahapan-tahapan solusi. Setiap graf terdapat sumber node untuk kemudian secara strategi algoritma greedy dilakukan pencarian minimal bobot terkecil sehingga didapati nilai terpendek yang merupakan rute atau jarak terpendek [2]. Contoh graf yang telah siap untuk memberikan jalur rute terpendek dapat dilihat pada Gambar 2.

Penelitian ini mengumpulkan 10 artikel yang menggunakan Algoritma Dijkstra untuk diterapkan di berbagai keperluan. Berbagai masalah berhasil diselesaikan dengan Algoritma Dijkstra, antara lain penyelesaian Biobjective Shortest Path (BSP), pemilihan rute multi-objective, Dijkstra's graph, evakuasi keadaan emergency, furzy, kaitannya dengan Location-based Service (LBS), dan penyelesaian dalam kasus penentuan distribusi rute optimal. Untuk memudahkan pengumpulan hasil pencarian, maka penelitian ini menggunakan tabel yang terdiri atas referensi judul penelitian, peneliti, tujuan, hasil yang mendapatkan benefit, dan kelemahan yang dimungkinkan terjadi. Secara lebih detail, dapat disimak dalam Tabel 1.

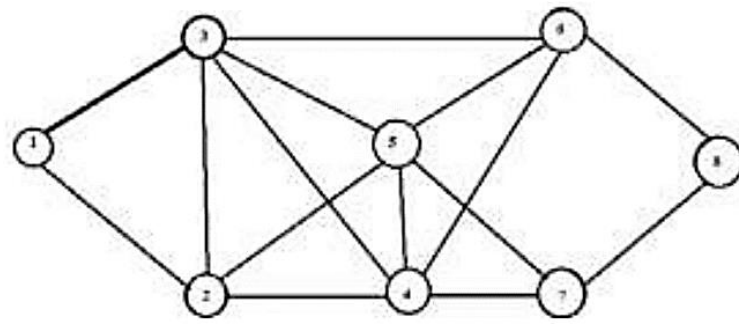

Gambar 2. Ilustrasi Contoh Graf non-directional. Sumber [2] 
Tabel 1. Penggunaan Algoritma Dijkstra untuk Berbagai Keperluan

\begin{tabular}{|c|c|c|c|c|c|}
\hline No & Judul & Peneliti & Tujuan & Manfaat & Kekurangan \\
\hline 1 & $\begin{array}{l}\text { A biobjective Dijkstra } \\
\text { algorithm }\end{array}$ & $\begin{array}{l}\text { Sedeño- } \\
\text { noda \& } \\
\text { Colebrook } \\
(2019)\end{array}$ & $\begin{array}{l}\text { Untuk mendapatkan metode baru } \\
\text { yang mirip Dijkstra dalam } \\
\text { menemukan semua titik yang } \\
\text { tidak didominasi pada masalah } \\
\text { one-to-all BSP. }\end{array}$ & $\begin{array}{l}\text { Memberikan metode baru } \\
\text { dengan menggunakan } \\
\text { Algoritma baru untuk } \\
\text { masalah BSP dalam } \\
\text { Algoritma Dijkstra yang } \\
\text { merupakan salah satu } \\
\text { jenis Algoritma pencarian } \\
\text { AI. }\end{array}$ & $\begin{array}{l}\text { Label akan dikurangi, } \\
\text { tidak dapat digunakan } \\
\text { untuk menyelesaikan } \\
\text { nondominated solutions. }\end{array}$ \\
\hline 2 & $\begin{array}{l}\text { A Three-Dimensional } \\
\text { Dijkstra's algorithm } \\
\text { for multi-objective } \\
\text { ship voyage } \\
\text { optimization }\end{array}$ & $\begin{array}{l}\text { Wang et al. } \\
\text { (2019) }\end{array}$ & $\begin{array}{l}\text { Untuk menentukan jalur yang } \\
\text { optimal menggunakan Algoritma } \\
\text { Dijkstra tipe multi-objective untuk } \\
\text { rute kapal 3D. }\end{array}$ & $\begin{array}{l}\text { Implementasi Algoritma } \\
\text { Dijkstra untuk mencari } \\
\text { rute rencana kapal terbaik } \\
\text { dengan konsumsi bahan } \\
\text { bakar kapal yang lebih } \\
\text { rendah dan waktu } \\
\text { pelayaran tiba secara } \\
\text { akurat. }\end{array}$ & $\begin{array}{l}\text { Tidak } \\
\text { mempertimbangkan } \\
\text { kelengkungan } \\
\text { permukaan bumi. }\end{array}$ \\
\hline 3 & Dijkstra graphs & $\begin{array}{l}\text { Bento et al. } \\
(2019)\end{array}$ & $\begin{array}{l}\text { Merumuskan Algoritma yang } \\
\text { efisien dengan grafik Dijkstra } \\
\text { untuk menentukan Algoritma } \\
\text { terstruktur atau bukan. }\end{array}$ & $\begin{array}{l}\text { Menjelaskan grafik } \\
\text { Dijkstra dengan } \\
\text { menjelaskan Algoritma } \\
\text { isomorfisme. }\end{array}$ & $\begin{array}{l}\text { Sulit untuk } \\
\text { menyelesaikan masalah } \\
\text { homeomorfisme 2- } \\
\text { kompleks. }\end{array}$ \\
\hline 4 & $\begin{array}{l}\text { EvacuSafe: A real-time } \\
\text { model for building } \\
\text { evacuation based on } \\
\text { Dijkstra's algorithm }\end{array}$ & $\begin{array}{l}\text { Mirahadi \& } \\
\text { McCabe } \\
(2020)\end{array}$ & $\begin{array}{l}\text { Sebuah model dirancang untuk } \\
\text { memantau gedung secara real-time } \\
\text { dan jika terjadi peristiwa tak } \\
\text { terduga, perubahan pada strategi } \\
\text { evakuasi darurat bagi penghuni } \\
\text { gedung menggunakan Active } \\
\text { Dynamic Signage System (ADSS). }\end{array}$ & $\begin{array}{l}\text { Implementasi Algoritma } \\
\text { Dijkstra untuk } \\
\text { membangun perangkat } \\
\text { lunak manajemen } \\
\text { evakuasi (aplikasi } \\
\text { EvacuSafe). }\end{array}$ & $\begin{array}{l}\text { Tidak } \\
\text { mempertimbangkan } \\
\text { kelengkungan } \\
\text { permukaan bumi. }\end{array}$ \\
\hline 5 & $\begin{array}{l}\text { Fuzzy Dijkstra } \\
\text { algorithm for shortest } \\
\text { path problem under } \\
\text { uncertain environmen }\end{array}$ & $\begin{array}{l}\text { Deng et al. } \\
(2012)\end{array}$ & $\begin{array}{l}\text { Untuk menentukan penjumlahan } \\
\text { dua sisi, dan membandingkan } \\
\text { jarak antara dua rute berbeda } \\
\text { dengan panjang sisi yang diwakili } \\
\text { bilangan fursy. }\end{array}$ & $\begin{array}{l}\text { Menggunakan furzy untuk } \\
\text { menyelesaikan SPP di } \\
\text { lingkungan yang tidak } \\
\text { pasti }\end{array}$ & $\begin{array}{l}\text { Fungsi keanggotaan fuгzy } \\
\text { harus tepat dan sesuai. }\end{array}$ \\
\hline 6 & $\begin{array}{l}\text { Geofence Index: A } \\
\text { Performance } \\
\text { Estimator for the } \\
\text { Reliability of Proactive } \\
\text { Location-based } \\
\text { Services }\end{array}$ & $\begin{array}{l}\text { Garzon et } \\
\text { al. (2017) }\end{array}$ & $\begin{array}{l}\text { Untuk meningkatkan penduga } \\
\text { reliability LBS proaktif yang } \\
\text { mengalami ketidaktentuan } \\
\text { reliability. }\end{array}$ & $\begin{array}{l}\text { Indeks geofence dapat } \\
\text { ditingkatkan untuk LBS } \\
\text { proaktif yang lebih baik } \\
\text { dari modul GPS yang } \\
\text { telah diadopsi. }\end{array}$ & $\begin{array}{l}\text { Apakah dapat } \\
\text { diimplementasikan } \\
\text { untuk gadget GPS } \\
\text { khusus? }\end{array}$ \\
\hline 7 & $\begin{array}{l}\text { Implementation of } \\
\text { Dijkstra Algorithm } \\
\text { and Multi-Criteria } \\
\text { Decision- } \\
\text { Implementation of } \\
\text { Dijkstra Algorithm } \\
\text { and Multi-Criteria } \\
\text { Decision- } \\
\text { Making for Optimal } \\
\text { Route Distribution }\end{array}$ & $\begin{array}{l}\text { Rosita et al. } \\
\text { (2019) }\end{array}$ & $\begin{array}{l}\text { Cara yang lebih sederhana untuk } \\
\text { memutuskan distribusi rute yang } \\
\text { optimal dengan seperangkat } \\
\text { parameter. }\end{array}$ & $\begin{array}{l}\text { Untuk mengatasi } \\
\text { distribusi rute yang } \\
\text { optimal dapat } \\
\text { menggunakan Algoritma } \\
\text { Dijkstra \& Algoritma } \\
\text { MCDM. }\end{array}$ & $\begin{array}{l}\text { Penentuan distribusi rute } \\
\text { optimal memerlukan } \\
\text { kombinasi dua algoritma. }\end{array}$ \\
\hline 8 & $\begin{array}{l}\text { Integrating Dijkstra's } \\
\text { algorithm into deep } \\
\text { inverse reinforcement } \\
\text { learning for food } \\
\text { delivery route } \\
\text { planning }\end{array}$ & $\begin{array}{l}\text { Liu et al. } \\
(2020)\end{array}$ & $\begin{array}{l}\text { Mengembangkan Algoritma deep } \\
\text { inverse reinforcement learning (IRL) } \\
\text { untuk menangkap preferensi } \\
\text { pengirim dari lintasan GPS } \\
\text { historis dan merekomendasikan } \\
\text { rute pilihan. }\end{array}$ & $\begin{array}{l}\text { Algoritma Dijkstra dapat } \\
\text { meningkatkan IRL untuk } \\
\text { rekomendasi rute } \\
\text { pengiriman makanan. }\end{array}$ & $\begin{array}{l}\text { Optimalisasi deep learning } \\
\text { perlu dilakukan. }\end{array}$ \\
\hline 9 & $\begin{array}{l}\text { Path Optimization } \\
\text { Study for Vehicles } \\
\text { Evacuation Based on } \\
\text { Dijkstra algorithm }\end{array}$ & $\begin{array}{l}\text { Chen et al. } \\
\text { (2014) }\end{array}$ & $\begin{array}{l}\text { Memodelkan metode prediksi } \\
\text { pemilihan jalur evakuasi darurat di } \\
\text { tempat umum terutama ketika } \\
\text { kondisi kepadatan penduduk } \\
\text { tinggi. }\end{array}$ & $\begin{array}{l}\text { Kita dapat menerapkan } \\
\text { Algoritma Dijkstra untuk } \\
\text { situasi darurat seperti } \\
\text { kondisi padat penduduk. }\end{array}$ & $\begin{array}{l}\text { Apakah dapat diintegrasi } \\
\text { dengan fungsi LBS pada } \\
\text { GPS-module? }\end{array}$ \\
\hline 10 & $\begin{array}{l}\text { The Improved } \\
\text { Dijkstra's Shortest } \\
\text { Path Algorithm and } \\
\text { Its Application }\end{array}$ & $\begin{array}{l}\text { Wang } \\
(2012)\end{array}$ & $\begin{array}{l}\text { Percobaan untuk tiga masalah } \\
\text { (pernyataan masalah) rute } \\
\text { terpendek untuk diselesaikan } \\
\text { secara efektif. }\end{array}$ & $\begin{array}{l}\text { Algoritma Dijkstra dapat } \\
\text { ditingkatkan dengan } \\
\text { "label-label", ini penting } \\
\text { untuk penelitian lanjutan. }\end{array}$ & $\begin{array}{l}\text { Memerlukan penelitian } \\
\text { lebih lanjut. }\end{array}$ \\
\hline
\end{tabular}

Algoritma Dijkstra menawarkan solusi untuk menentukan rute terpendek melalui serangkaian perhitungan bobot minimum setiap node dengan masingmasing pemberian label tertentu. Sedeño-noda \& Colebrook [8] memberikan alternatif untuk penyelesaian kasus biobjective shortest path (BSP) dengan kondisi titik yang tidak didominasi pada masalah one-to-all BSP. Wang [7] menggunakan label-label yang ditingkatkan agar dapat menyelesaikan permasalahan tiga kasus sekaligus. Algoritma Dijkstra sangat berperan dalam kedua masalah ini dan perlu penelitian lebih lanjut untuk mengoptimalkan peran label pada Algoritma Dijkstra.

Penelitian ini mendapati artikel yang dimungkinkan terdapat kekurangan dalam implementasi perhitungan 
jarak terdekat, berupa pertimbangan dalam kondisi kelengkungan permukaan bumi. Memang algoritma yang tepat untuk menyelesaikan permasalahan penentuan rute terdekat dengan mempertimbangkan kelengkungan permukaan bumi adalah salah satunya Algoritma Haversine Formula [15], [16], [17], [18], [19], [20]. Namun, tidak menutup kemungkinan apabila di masa mendatang pengembangan antara Algoritma Dijkstra dengan Algoritma Haversine Formula dapat dilakukan untuk menghasilkan kombinasi yang lebih baik dalam menentukan jarak atau rute terpendek suatu titik yang ada di permukaan bumi. Berdasarkan review yang penelitian ini lakukan, secara ilustrasi penggunaan Algoritma Dijkstra untuk berbagai masalah dapat disimak dalam Gambar 3.

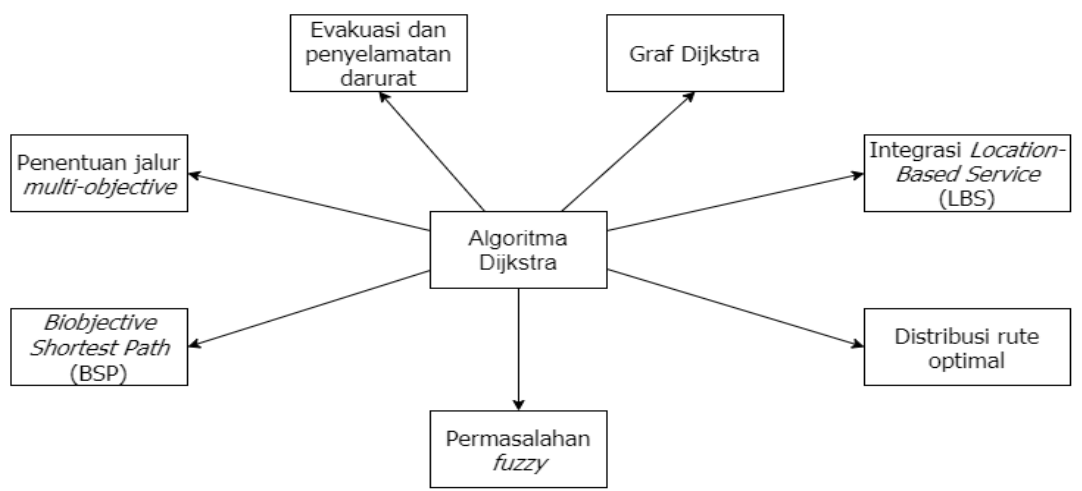

Gambar 1. Penggunaan Algoritma Dijkstra untuk berbagai masalah

Kombinasi dua algoritma dalam penyelesaian suatu masalah dapat dilakukan seperti pada penelitian Rosita et al. [5] yang menggunakan dua gabungan algoritma dalam menyelesaikan permasalahan distribusi rute optimal untuk suatu kasus dan menghasilkan jaringan rute terpendek optimal. Penggabungan kedua algoritma tersebut yaitu Algoritma Dijkstra dengan Algoritma MCDM (Multi Criteria Decision Making). Algoritma MCDM merupakan algoritma untuk membangun sistem pendukung keputusan. Algoritma MCDM berisi kriteriakriteria tertentu yang telah disepakati dan harus dipenuhi oleh sistem sehingga persyaratan kriteria yang ada dilakukan melalui cara mengurut dari tingkatan rendah ke tingkatan tinggi (ranking) [21]. Namun, dalam hal ini karena memerlukan dua kombinasi algoritma maka ada kemungkinan terdapat miss-conception terhadap gabungan algoritma apabila tidak dilakukan penyelesaian masalah (solusi) secara akurat dan antar-algoritma saling mendukung satu sama lain. Kombinasi Algoritma Dijkstra dengan Algoritma MCDM dalam menentukan rute terpendek dan menghasilkan jaringan rute terpendek optimal dapat dilihat secara ilustrasi pada Gambar 4.

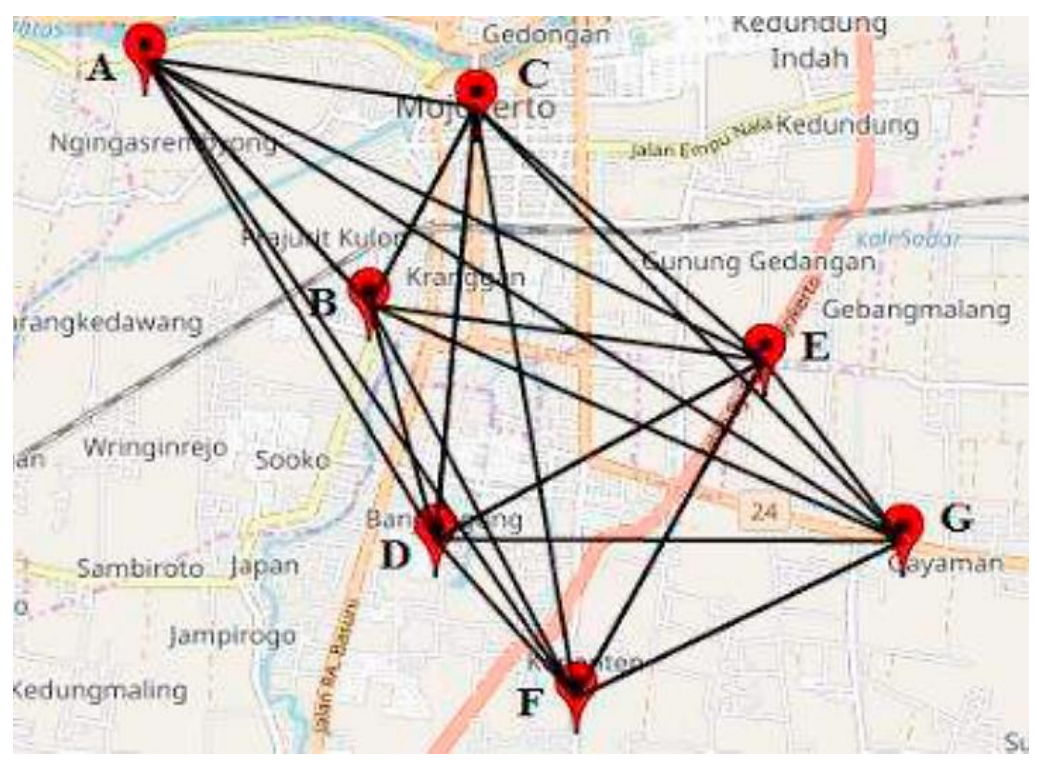

Gambar 2. Jaringan Rute Optimal untuk Menentukan Rute Terpendek dengan Gabungan Algoritma Dijkstra dan Algoritma MCDM. Sumber [5].

Penggunaan Algoritma Dijkstra untuk kaitannya dengan fitur Global Positioning System (GPS) seperti pada penelitian Garzon et al. [4] dan Chen et al. [6] yang masing-masing mencoba menerapkan Algoritma Dijkstra pada permasalahan lokasi yang berbasis real-time, sehingga fitur GPS digunakan. Namun, penelitian [4] mencoba 
memberikan solusi dari ketidakakuratan modul GPS yang sudah ada untuk sisi realibility-nya. Dengan menggunakan Algoritma Dijkstra, realibility dari fitur GPS "geofence" dapat ditingkatkan untuk lebih akurat lagi. Pengembangan geofence lebih lanjut yang terintegrasi dengan GPS dapat digunakan untuk monitoring secara realtime lokasi berbasis GPS [22] dan digunakan untuk mengukur kemampuan geo-triggering dengan mempertimbangkan akurasi, reliabilitas, dan konsumsi baterai berdasarkan titik lokasi dilacak dan arah trigger-nya [23]. Sedangkan [6] dalam kasus evakuasi kendaraan untuk kondisi darurat. Secara teknis, kejadian evakuasi darurat memerlukan perhitungan teliti dalam proses evakuasinya sehingga akan tercipta tingkat keselamatan yang tinggi. Namun, jika ditelisik, keadaan darurat apalagi berada di sekitar lokasi yang padat penduduknya, maka tingkat akurasi proses evakuasi harus akurat, dalam hal ini peran Algoritma Dijkstra yang diintegrasi dengan fitur GPS tentunya akan menghasilkan proses evakuasi yang lebih baik dan tingkat keselamatan yang tinggi.

Penggunaan Algoritma Dijkstra untuk berbagai masalah dapat menghasilkan manfaat yang dapat memudahkan pekerjaan manusia di dunia nyata apabila diimplementasikan. Dengan tingkat akurasi yang baik serta menghasilkan solusi rute terpendek yang cukup akurat membuat Algoritma Dijkstra lebih unggul digunakan untuk penyelesaian masalah lebih dari dua masalah jarak yang bersamaan. Disisi lain, Algoritma Dijkstra menawarkan kemudahan untuk digunakan bersamaan dengan algoritma lainnya. Keunggulan yang terdapat pada Algoritma Dijkstra dalam menyelesaikan masalah rute terpendek tentu juga ditemukan beberapa kemungkinan kekurangannya. Perlu penelitian lebih lanjut untuk mengetahui dan mencari solusi dari adanya kekurangan yang ditimbulkan dari Algoritma Dijkstra untuk berbagai keperluan penyelesaian masalah rute terpendek.

\section{KESIMPULAN}

Penelitian ini menyimpulkan bahwa penggunaan Algoritma Dijkstra dapat dimanfaatkan untuk berbagai keperluan, seperti penyelesaian biobjective shortest path (BSP), penentuan jalur multi-objective, graf Dijkstra, evakuasi darurat, permasalahan fuzqy, integrasi dengan fitur location-based service (LBS), dan distribusi rute optimal.

\section{UCAPAN TERIMA KASIH}

Ucapkan terima kasih disampaikan kepada Jakarta Global University yang telah memberikan kesempatan dan dukungan untuk kelancaran jalannya penelitian ini.

\section{DAFTAR PUSTAKA}

[1] M. Qomaruddin, M. T. Alawy, and S. Sugiono, "Perancangan Aplikasi Penentu Rute Terpendek Perjalanan Wisata di Kabupaten Jember Menggunakan Algoritma Dijkstra," Sci. Electro, vol. 6, no. 2, pp. 31-39, 2018.
[2] D. Wahyuningsih and E. Syahreza, "Shortest Path Search Futsal Field Location with Dijkstra Algorithm," IJCCS (Indonesian J. Comput. Cybern. Syst., vol. 12, no. 2, p. 161, 2018, doi: 10.22146/ijccs.34513.

[3] Farid and Y. Yunus, "Analisa Algoritma Haversine Formula untuk Pencarian Lokasi Terdekat Rumah Sakit dan Puskesmas Provinsi Gorontalo," Ilk. J. Ilm., vol. 9, no. 3, pp. 353-355, 2017.

[4] S. R. Garzon, D. Arbuzin, and A. Kupper, "Geofence index: A performance estimator for the reliability of proactive location-based services," Proc. - 18th IEEE Int. Conf. Mob. Data Manag. MDM 2017, pp. 1-10, 2017, doi: 10.1109/MDM.2017.12.

[5] Y. D. Rosita, E. E. Rosyida, and M. A. Rudiyanto, "Implementation of Dijkstra Algorithm and MultiCriteria Decision-Making for Optimal Route Distribution," Procedia Comput. Sci., vol. 161, pp. 378-385, Jan. 2019, doi: 10.1016/j.procs.2019.11.136.

[6] Y. Z. Chen, S. F. Shen, T. Chen, and R. Yang, "Path Optimization Study for Vehicles Evacuation-based on Dijkstra Algorithm," in Procedia Engineering, Jan. 2014, vol. 71, pp. 159-165, doi: 10.1016/j.proeng.2014.04.023.

[7] S. X. Wang, "The improved Dijkstra's Shortest Path Algorithm and Its Application," in Procedia Engineering, Jan. 2012, vol. 29, pp. 1186-1190, doi: 10.1016/j.proeng.2012.01.110.

[8] A. Sedeño-noda and M. Colebrook, "A Biobjective Dijkstra Algorithm,” Eur. J. Oper. Res., vol. 276, no. 1, pp. 106-118, 2019, doi: 10.1016/j.ejor.2019.01.007.

[9] H. Wang, W. Mao, and L. Eriksson, "A ThreeDimensional Dijkstra's Algorithm for MultiObjective Ship Voyage Optimization," Ocean Eng., vol. 186, no. May, p. 106131, 2019, doi: 10.1016/i.oceaneng.2019.106131.

[10] L. M. S. Bento, D. R. Boccardo, R. C. S. Machado, F. K. Miyazawa, V. G. Pereira de Sá, and J. L. Szwarcfiter, "Dijkstra graphs," Discret. Appl. Math., vol. 261, pp. 52-62, 2019, doi: 10.1016/j.dam.2017.07.033

[11] F. Mirahadi and B. Y. McCabe, "EvacuSafe: A RealTime Model for Building Evacuation-based on Dijkstra's Algorithm," J. Build. Eng., no. June, p. 101687, 2020, doi: 10.1016/j.jobe.2020.101687.

[12] Y. Deng, Y. Chen, Y. Zhang, and S. Mahadevan, "Fuzzy Dijkstra Algorithm for Shortest Path Problem Under Uncertain Environment," Appl. Soft Comput. J., vol. 12, no. 3, pp. 1231-1237, 2012, doi: 10.1016/j.asoc.2011.11.011.

[13] S. Liu, H. Jiang, S. Chen, J. Ye, R. He, and Z. Sun, "Integrating Dijkstra's Algorithm into Deep Inverse Reinforcement Learning for Food Delivery Route Planning," Transp. Res. Part E Logist. Transp. Rev., vol. 142, no. May, p. 102070, 2020, doi: 10.1016/j.tre.2020.102070. 
[14] Y. Z. Chen, S. F. Shen, T. Chen, and R. Yang, "Path Optimization Study for Vehicles Evacuation-based on Dijkstra algorithm," Procedia Eng., vol. 71, pp. 159-165, 2014, doi: 10.1016/j.proeng.2014.04.023.

[15] R. R. Al Hakim, M. Y. Billian, and A. Muchsin, "Pendekatan Postulat Jarak Terdekat Rumah Sakit Rujukan Covid-19 di Keresidenan Surakarta Indonesia Menggunakan Haversine Formula," SEMASTER Semin. Nas. Teknol. Inf. Ilmu Komput., vol. 1, no. 1, pp. 103-111, 2020, doi: 10.31849/semaster.v1i1.

[16] R. Ariyanto, Y. Watequlis Syaifudin, D. Puspitasari, A. Yuli Ananta, A. Setiawan, and E. Rohadi, "A Web and Mobile GIS for Identifying Areas within the Radius Affected by Natural Disasters Based on OpenStreetMap Data," Int. J. Online Biomed. Eng., vol. 15, no. 15, pp. 80-95, Dec. 2019, doi: 10.3991/ijoe.v15i15.11507.

[17] A. M. Ahmed, "Designing a Framework to Control the Spread of Covid-19 by Utilizing Cellular System," Kurdistan J. Appl. Res., vol. 5, no. 3, pp. 146-153, Jun. 2020, doi: 10.24017/covid.16.

[18] K. Saputra, N. Nazaruddin, D. H. Yunardi, and R. Andriyani, "Implementation of haversine formula on location based mobile application in syiah kuala university," in Proceedings: Cyberneticscom 2019 - IEEE International Conference on Cybernetics and Computational Intelligence: Towards a Smart and Human-Centered Cyber World, Aug. 2019, pp. 40-45, doi: 10.1109/cyberneticscom.2019.8875686.

[19] A. Suryana, F. Reynaldi, F. Pratama, G. Ginanjar, I. Indriansyah, and D. Hasman, "Implementation of Haversine Formula on The Limitation of E-Voting Radius Based on Android," in Proceedings - 2018 4th International Conference on Computing, Engineering, and Design, ICCED 2018, Apr. 2019, pp. 218-223, doi: 10.1109/ICCED.2018.00050.

[20] C. Husada, K. D. Hartomo, and H. P. Chernovita, "Implementasi Haversine Formula untuk Pembuatan SIG Jarak Terdekat ke RS Rujukan COVID-19," J. RESTI, vol. 4, no. 5, pp. 874-883, 2020.

[21] A. N. Pramudhita, H. Suyono, and E. Yudaningtyas, "Penggunaan Algoritma Multi Criteria Decision Making dengan Metode Topsis dalam Penempatan Karyawan," J. EECCIS, vol. 9, no. 1, pp. 91-94, 2015.

[22] A. H. Abbas, M. I. Habelalmateen, S. Jurdi, L. Audah, and N. A. M. Alduais, "GPS Based Location Monitoring System with Geo-Fencing Capabilities," in AIP Conference Proceedings, 2019, vol. 2173, p. 20004, doi: 10.1063/1.5133929.

[23] M. Alsaqer, B. Hilton, T. Horan, and O. Aboulola, "Performance Assessment of Geo-triggering in Small Geo-fences: Accuracy, Reliability, and Battery Drain in Different Tracking Profiles and Trigger Directions," Procedia Eng., vol. 107, pp. 337-348, 2015, doi: 10.1016/j.proeng.2015.06.090. 